\title{
AUTOMUTILAÇÃO E SAÚdE PÚBLICA: DESAFIOS DA CONTEMPORANEIDADE
}

\section{ARTIGO ORIGINAL}

VIEIRA, Francielly Cardoso ${ }^{1}$

VIEIRA, Francielly Cardoso. Automutilação e saúde pública: desafios da contemporaneidade. Revista Científica Multidisciplinar Núcleo do Conhecimento. Ano 04, Ed. 12, Vol. 02, pp. 81-101. Dezembro de 2019. ISSN: 2448-0959, Link de acesso: https://www.nucleodoconhecimento.com.br/saude/automutilacao-e-saude

\section{RESUMO}

A automutilação que durante muito tempo foi considerada como um comportamento suicida, na atualidade, tem despertado o interesse da área científica após ganhar maior visibilidade dada pela mídia e pela sua crescente manifestação na sociedade. A automutilação se mostra como um desafio para muitos profissionais de saúde pública, uma vez que, apesar da sua importância, ainda não há um consenso na terminologia e definição da mesma. O profissional se depara com indivíduos que estão em situação de sofrimento, e isto demanda a necessidade do desenvolvimento de um tratamento eficaz e também de formas de prevenção, pois a saúde pública atual deixou de ficar presa apenas nas atividades de prevenção primária e terciária, como também é considerada de grande importância nas etapas de diagnóstico e no tratamento de doenças. Para a compreensão dessa temática, foi concretizada uma revisão bibliográfica em livros, sites, artigos, entre outras fontes, objetivando construir uma pesquisa sólida e calcada em conhecimentos trazidos por pesquisadores do tema.

1 Especialização em Saúde Pública, Saúde Mental e Dependência Química. Graduação em Psicologia. 
Palavras-chaves: Automutilação, saúde pública, corporeidade.

\section{INTRODUÇÃO}

A imagem corporal está em constante construção, que tem início no momento do nascimento e vai até a morte do indivíduo. Essa construção é resultado do processamento dos estímulos que este indivíduo se depara no decorrer da sua vida.

$\mathrm{Na}$ construção da subjetividade do indivíduo na contemporaneidade, pode se observar uma comunicação através do corpo, como fonte de sofrimento, o surgimento de autolesões que costumam acompanhar processos da fase da adolescência associada a quadros psicológicos de transtornos na oralidade e na imagem do próprio corpo.

A automutilação não é uma prática nova, já se apresenta há muito tempo na história, mas apesar disto, até o atual momento não existem pesquisas empíricas e dados consistentes sobre a automutilação no Brasil, sendo os estudos desta temática analisado de maneira informal, por meio de blogs e redes sociais, usados para identificação de usuários que praticam a automutilação e para a troca de informação entre eles. Então nos últimos anos, a partir da atenção dada pela mídia, o interesse pelas causas e tratamentos da automutilação vem mostrando um crescimento considerável.

Durante muito tempo o comportamento de punir o próprio corpo através de autolesões, foi compreendido como parte de um conjunto de fenômenos associados ao comportamento suicida. O primeiro avanço com relevância que trouxe esta temática foi promovido pelo psicanalista e psiquiatra graduado em Harvard, Karl Menninger $(1938)^{1}$, no livro: Man against hinself. O livro propõe a ideia que a automutilação seria uma ação do indivíduo para evitar o suicídio e tranquilizar-se. Ideia esta que ainda é adotada como pressuposto para os atuais estudos.

Menninger escreveu uma visão teórica psicanalista. Ele acreditava que a automutilação continha como um dos elementos essenciais: agressão voltada para o interior, que frequentemente é sentida em relação a um objeto exterior de amor-ódio, 
geralmente um dos dois, estimulação, como uma intenção sexual ou puramente física, e uma função autopunitiva que permite que a pessoa a compense ou pague por um "pecado" de natureza agressiva ou sexual (STRONG, 1998 apud ARAÚJO et al. 2016).

Segundo Giusti (2013), pode ter uma ligação com vários fatores, dentre eles destacam-se as alterações funcionais e neurobiológicas. Uma vez que, os sistemas com principal associação a este comportamento são os serotominérgicos, dopaminérgicos e opioides.

O comportamento mutilante pode se manifestar tanto na situação de uma doença, quanto na ausência desta. Assim, estando presente em várias doenças e de várias formas diferentes, a identificação desses formatos pode contribuir para entender o que causou esse comportamento e também como seguir com o tratamento. A intensidade, forma, agressividade, envolvimento emocional, magnitude e o grau de dano corporal vária de caso para caso, tornando-se necessário uma análise detalhada de cada caso para encontrar o tratamento adequado.

A Automutilação vem se mostrando um problema de saúde pública por sua crescente exposição e manifestação na sociedade. Segundo o autor George (2011), a saúde pública na atualidade tem a necessidade de uma convivência harmônica, aberta e respeitosa com a comunicação social. Com o interesse de assegurar a promoção de saúde à população, e assim criar condições favoráveis ao desenvolvimento humano.

O referente trabalho trata-se de que um estudo de abordagem qualitativa, caracterizando-se por não medir ou enumerar, e sim: descrever, analisar, compreender certas variáveis e processos vivenciados por grupos sociais, (GIL, 2008). O presente estudo, com início em julho de 2018, no qual foram consultados livros, artigos científicos e dissertações de mestrado e doutorado, irá analisar como a automutilação tem impacto na sociedade e na saúde pública contemporânea. Além disso, seguirá os preceitos do estudo descritivo, onde as pesquisas deste tipo têm como objetivo primordial a descrição das características de determinada população ou fenômeno ou o estabelecimento de relações entre variáveis, (GIL, 2008). 
Ademais, trata- se de uma pesquisa bibliográfica, que é um apanhado geral sobre os principais trabalhos já realizados, revestidos de importância, por serem capazes de fornecer dados atuais e relevantes, relacionados com o tema. $O$ estudo da literatura pertinente pode ajudar a planificação do trabalho, evitar publicações e certos erros, e representa uma fonte indispensável de informações, podendo até orientar as indagações (LAKATOS; MARCONI, 2003).

\section{CONCEPÇÃO DE CORPO E AUTOMUTILAÇÃO}

O corpo, cada vez mais, está sendo utilizado como forma de expressar a sua própria subjetividade e a subjetividade do meio que está inserido. O corpo é uma forma de comunicação com o meio, utilizada muitas vezes como válvula de escape para sofrimentos e angústias que o indivíduo se depara no decorrer de sua vida.

Mataruna (2004) define o termo imagem corporal ou esquema corporal como a constituição estruturada do próprio corpo na mente do indivíduo, isso ocasiona um conjunto de sensações sinestésicas constituídas pelos sentidos e das experiências vividas. Essa imagem pode ser tátil, auditiva, visual, motora, entre outras, onde é necessário que seja analisada como um conjunto e não de forma separada. Para Merleau Ponty (1945-1994, apud NÓBREGA 2008), não há uma preocupação em diferenciar o corpo como sujeito e como objeto, e sim, em ter uma ideia de corpo ativo e em constante interação com o meio e com as pessoas nele inserido. Aqui o corpo capta as sensações que vem do meio externo e também serve como meio de expressão da subjetividade do indivíduo a que pertence.

Segundo Ferreira (2013), corporeidade são várias representações concretas, que vão definir o ser social de cada indivíduo, assim criando uma imagem corporal, que contribuirá na construção de cada um. Nesse processo será formado o esquema de um corpo, partindo da ideia que o corpo tem a necessidade de teorizar um olhar de suas experiências. A imagem corporal está em constante reelaboração, que tem início no nascimento e vai até a morte. Esta reelaboração é resultado do processamento dos estímulos que o indivíduo encontra ao longo de sua vida. 
$\mathrm{Na}$ infância, o indivíduo inicia o desenvolvimento do conceito da imagem corporal, e este irá evoluir durante o trajeto de sua vida e já estará elaborada, geralmente, aos cinco anos de idade (MATARUNA, 2004). O corpo infantil se perde e dá início a fase da adolescência, esta fase é repleta de experiências que podem ocorrer e serem acompanhadas de confusão mental, então o indivíduo não se reconhece e pode não compreender o que está acontecendo, essa incompreensão pode levar esse indivíduo a uma série de comportamentos e atitudes na tentativa de reaver o controle sobre si e sobre as coisas que acontecem com o seu corpo (FROIS; MOREIRA; STENOEL, 2011).

Ao deixar o corpo infantil, o indivíduo passa por um processo acelerado de transformações e diante das incompreensões e das mudanças corporais e emocionais, pode ocasionar uma instabilidade afetiva e o surgimento de possíveis transtornos, podendo ser de ordem psicológica ou física. Se nessa fase há uma dificuldade maior em compreender e expressar suas emoções, o indivíduo pode recorrer a meios de transferir o desconforto emocional para outro local, podendo este local ser o próprio corpo, resultando em uma linguagem corporal onde cada vez mais o corpo é utilizado como instrumento da manifestação do seu mal-estar. Essa comunicação por meio de atos pode ser incompreendida ou despercebida.

$\mathrm{Na}$ construção da subjetividade na contemporaneidade, pode se observar nesta comunicação através do corpo, uma fonte de sofrimento e o surgimento de autolesões que costumam acompanhar processos da fase da adolescência associados a quadros psicológicos de transtornos na oralidade e da imagem do próprio corpo. De acordo com Brizni (2014) as marcas no corpo são uma expressão do sofrimento do indivíduo, uma forma de comunicação corporal, que este encontrou para representar suas angústias, angústias estas que o indivíduo não consegue transmitir por meio da linguagem oral. Punir o próprio corpo é uma maneira encontrada de sinalizar que algo não está bem.

A automutilação, não é uma prática nova, já se apresenta há muito tempo na história, porém, até o atual momento não existem pesquisas empíricas e dados consistentes sobre a automutilação no Brasil, sendo os estudos desta temática analisados de 
maneira informal, através de blogs e redes sociais. Estas são usadas para a identificação de usuários que praticam a automutilação e para a troca de informações entre eles.

Para Giusti (2013) o interesse pela automutilação vem mostrando um crescimento nos últimos 20-30 anos, em parte, devido à atenção dada pela mídia, porém apesar deste crescimento ainda há muito a se estudar sobre essa temática. Segundo Turner (2002), o primeiro artigo feito sobre a automutilação na literatura médica, em 1846, foi um relato de um caso de uma mulher viúva e maníaco-depressiva, de 48 anos, que por sentir que os seus olhos a levavam a desejar os homens, que para ela era considerado como um pecado pelo fato de ser viúva e, acabou por removê-los.

A partir da metade do século XIX, nos Estados Unidos, foram elaborados vários artigos de estudos de casos na literatura médica, que relatam sobre as formas mais severas de automutilação. Nos anos 60 , os estudos psiquiátricos em automutilação tiveram como foco os cortes em punhos, esses artigos eram principalmente sobre psicóticos que apresentavam incidentes isolados de automutilação extrema, os quais eram geralmente induzidos por alucinações ou ilusões com o fundo religioso (ARAÚJO, et al. 2016).

O primeiro avanço com relevância que trouxe esta temática foi promovido pelo psicanalista e psiquiatra graduado em Harvard, Karl Menninger (1938), em seu livro: Man against hinself. Onde propõe a ideia que a automutilação seria uma ação do indivíduo para evitar o suicídio e tranquilizar-se. Ideia esta que ainda é adotada como pressuposto para os atuais estudos. Menninger escreveu sobre uma visão teórica psicanalítica, ele acreditava que a automutilação continha como um dos elementos essenciais: agressão voltada para o interior, que frequentemente é sentida em relação a um objeto exterior de amor-ódio, geralmente um dos pais, estimulado, com uma intenção sexual ou puramente física, e uma função autopunitiva que permite que a pessoa compense ou pague por um "pecado" de natureza agressiva ou sexual (STRONG, 1998 apud ARAÚJO, et al. 2016). 
Para Menninger (1938/1966), a automutilação é uma negociação para que através dela não se chegasse ao suicídio. Já Silva (2012), propõe em seu trabalho: $O$ acesso ao tratamento médico como direito fundamental, que há relatos que na mitologia grega se identificam casos de automutilação e em especial a automutilação masculina. Aparentemente o primeiro caso é o caso do Deus Eshmun, que na tentativa de se livrar de assédios praticados pela deusa Astronae, castrou-se, por causa deste fato, a castração masculina recebeu o nome de complexo de Eshmun.

Em várias culturas primitivas, modernas e contemporâneas o corpo é usado como meio de comunicação com o mundo, podendo observar ao longo da história as marcas corporais que resultaram de lesões autoinfligidas. Costa (2014) em seu livro: Tatuagem e marcas corporais: atualizações do sagrado, traz um questionamento acerca do motivo que fez com que os homens começassem a fazer tatuagens, colocar piercings, ou mesmo mutilar-se. O autor também enfatiza os rituais que as sociedades tribais realizam com marcas corporais simbolizando rituais de passagem, como o de nascimento e o de morte.

Ao passar do tempo, o comportamento de automutilação vem despertando um maior interesse pela comunidade científica. Apesar de não haver um consenso sobre as causas desse comportamento, ele é ligado a transtornos mentais, onde gera relativa tranquilidade psíquica para aguentar a confusão mental, que ocasiona um grande impacto na vida do indivíduo que se automutila. Essa falta de consenso resulta em divergências nos resultados quanto, por exemplo, à prevalência, se realmente esse comportamento está aumentando ou não, se é mais prevalente em um dos gêneros.

A automutilação é precedida por um aumento de tensão, raiva de si mesmo, ansiedade, depressão, disforia e sensação de perda do controle. Os fatores precipitantes podem ter várias origens; independentemente destas, são comuns sensações de rejeição ou abandono (real ou não). As razões para a automutilação se sobrepõem no mesmo paciente (GIUSTI, 2013, p.6).

Ainda segundo as ideias de Karl Menninger (1938) os comportamentos de autosabotagem têm como base as ideias de Freud, do Supereu, onde os sentimentos de culpa em excesso, resultados de uma raiva contida, promoveriam agressões 
autodirigidas. Tais atitudes (as automutilações) ajudariam a lidar com esses sentimentos ou amenizar. Nessa perspectiva, a automutilação seria uma busca de cura ou da autopreservação, garantindo a não total autoaniquilação (suicídio). O indivíduo que se mutila, faz isto em busca de sentir-se melhor.

A automutilação pode ser compreendida como qualquer comportamento intencional envolvendo agressão direta ao próprio corpo sem intenção consciente de suicídio e não socialmente aceita dentro de sua própria cultura e nem para exibição [...] as lesões são geralmente superficiais e sem repercussões sistêmicas (GIUSTI, 2013, p.5).

Para Cedaro e Nascimento (2013), os indivíduos que se mutilam fazem isso por não conseguir lidar com emoções fortes, pressões externas e problemas de relacionamento, considerando como uma forma de administrar seus sentimentos pela via de atuação, no lugar de utilizar a comunicação oral. Machucar-se seria uma maneira de amenizar a angústia, gerando ao mesmo tempo dor e prazer.

Assim, a automutilação é uma maneira de expressar o não dito através da linguagem expressa pelo corpo. Essas mutilações trazem consigo, uma série de significados individuais que diferem de uma pessoa para outra desde punição, alívio, manipulação e inclusão em um grupo. A autolesão provoca uma liberação de endorfina no cérebro, que resulta em uma sensação de prazer, levando há uma repetição do ato.

O sentimento promovido pela primeira experiência nunca se repetirá da mesma maneira, então na segunda vez será necessária uma mutilação maior ou que precise de mais intensidade que a primeira, o que acaba causando um número cada vez maior de ações mutilatórias na tentativa de obter o mesmo prazer que encontrou no primeiro ato. Esses atos causam impacto na vida do indivíduo que o faz, e isto se deve ao fato de ser uma perturbação crônica de gravidade, e que causam intensos riscos físicos, sociais e educacionais.

A automutilação é uma questão clínica que tem aparecido com frequência nos consultórios dos psicólogos e psicanalistas, assim como nas escolas, especialmente entre os adolescentes. É também um tema tratado pela psiquiatria [...] uma forma de leitura dessa questão é que a automutilação se configura como um sintoma de alguns transtornos mentais. Na leitura médica e psiquiátrica, o sintoma é algo que 
geralmente deve ser eliminado (ou tratado) para que o sujeito volte ao estado anterior de saúde (ARAÚJO et al. 2016, p.498).

A ocorrência desse comportamento tem despertado uma preocupação cada vez maior, principalmente pelo fato que podem se apresentar em uma fase que pode ser bem problemática para várias pessoas. Estudantes, principalmente de escolas públicas, podem apresentar uma taxa elevada de risco de apresentar comportamentos automutilantes, com ou sem ideação suicida. De acordo com vários estudos, os comportamentos de automutilação são mais observados em indivíduos do sexo feminino e estão associados a níveis menores de educação, também se tem um maior índice de pessoas que apresentam maiores psicopatologias gerais, como a depressão, agressividade, ansiedade, etc.

O comportamento de automutilação vai para além do lugar de (in) visibilidade. Ao se automutilar, o adolescente torna visível sua dor. Ela, então, está marcada em seu corpo. Podemos supor que o comportamento de automutilação é uma tentativa de sair de um lugar de invisibilidade do corpo (BERNARDES, 2015, p.35).

A importância dos estudos acerca da automutilação tem como público alvo principalmente os adolescentes, pois este assunto mostra a necessidade de ser trabalhado de forma preventiva, com o objetivo de reduzir danos. Uma vez que, esta é uma fase de transição e de perda do corpo infantil para a construção de um novo corpo, é uma fase em que o indivíduo se reinventa, aprende e vivência experiências de forma mais intensa em vários aspectos de sua vida. Várias dessas mudanças podem ser vividas de forma conturbada por muitos de nós e, eventualmente, uma forma de extravasar precisa ser construída, para manifestar frustrações e vários outros pensamentos negativos que possam aparecer em relações interpessoais.

Parte da incompreensão acerca do porquê de uma pessoa se mutilar refere-se a uma pulsão primária dos seres humanos, que é a evitação da dor e a obtenção do Prazer (princípio do prazer). A prática da Automutilação inclui o auto de infligir dor a si próprio, o que é inconceptível para a maioria das pessoas. Vem daí também a dificuldade de discussão sobre o assunto, entre automutiladores e pessoas próximas, como familiares e amigos (ARAÚJO et al., 2016, p. 504). 
$\mathrm{Na}$ automutilação o indivíduo mantém um nível de controle sobre as lesões. Os resultados são planejados, desejados e visíveis. E ao realizar esse comportamento, muitas vezes acreditam que ninguém seja capaz de entender o que estão vivenciando, buscando em algumas situações o isolamento. Esquivando-se do contato com outras pessoas, por medo de uma possível incompreensão ou críticas que possam sofrer. Temem também que seus atos sejam descobertos, porque necessitam continuar praticando, além disso, apresentam certas dificuldades em falar sobre si mesmo, e ao descobrir que alguém passa por situação semelhante, costuma tentar ajudar para que ela pare com essa conduta, pois tem consciência de que esse ato é nocivo.

Uma associação pode ser observada entre transtornos alimentares e os comportamentos automutilantes, este seria um fator de risco para tal, considerado pelo fato de haver insatisfação com o próprio corpo. Estudos recentes vêm mostrando que este comportamento pode acontecer em várias fases da vida, porém é mais acometida na adolescência, fase que pode ser vivida com muitas transformações, turbulências e desafios que podem causar dificuldades em suas relações sociais, mostrando uma ocorrência maior no sexo feminino.

O progresso nos estudos a cerca do comportamento da automutilação vem se mostrando de forma gradativa e trazendo informações muito importantes para a construção de uma definição, e assim esclarecendo para a sociedade e para os profissionais de saúde sobre essa doença, caminhando para um tratamento eficaz. Com um maior conhecimento os profissionais de saúde podem promover um serviço mais individualizado e focado na subjetividade das pessoas, e nos fatores que desencadearam o aparecimento desse comportamento automutilante, um olhar multidisciplinar é essencial para obter sucesso no tratamento adotado pela equipe de saúde pública.

\section{AUTOMUTILAÇÃO E SAÚDE PÚBLICA}

Por muito tempo, a automutilação foi considerada como parte de um conjunto de fenômenos associados ao comportamento suicida. Karl Meninger (1938) foi o primeiro a realizar essa distinção. Para Favazza (1996), automutilação é categorizada a partir 
da repetição dos seus episódios e do nível do dano físico causado, e assim considerada, mesmo que alguns discordem, como um fenômeno diferente do suicídio.

À medida que os adolescentes entram na fase adulta, pode-se observar que há uma diminuição desse comportamento automutilante, até que esse comportamento tenha um fim, sem muitas vezes, necessitar da intervenção de um profissional de saúde. Em grande parte dos casos, pode existir uma associação com os conflitos vivenciados na adolescência. Muitos estudiosos concordam com essa ideia, porém, a automutilação torna-se um problema de saúde pública, uma vez que, há um aumento significativo de indivíduos, principalmente adolescentes, que a praticam.

De acordo com a classificação estatística de doenças e problemas relacionados à saúde CID-10 (1999), a automutilação está inserida na categoria de transtornos dos hábitos e dos impulsos. É característica para o diagnóstico que, a pessoa repetitivamente não consiga resistir a impulsos que a leva a adotar este comportamento. Há um período padrômico de tensão seguido de uma sensação de alívio quando há a realização do ato. (CID-10, 1999, p.350).

Assim, a automutilação é um comportamento que resulta em danos no corpo do próprio indivíduo, mas sem a intenção de suicídio, pelo contrário, é considerado como uma forma de fuga. A forma que o indivíduo comete a mutilação pode fornecer pistas a respeito dos mecanismos que ocasionam este comportamento, podendo contribuir de forma significativa no desenvolvimento de um tratamento.

Segundo Neto (2014), o indivíduo quando se mutila está tentando buscar uma regulação de afetos, procurando se acalmar ou liberar pressão emocional que se acumulou dentro de significados. Também ele pode estar tentando criar limites interpessoais, demonstrando que está separado de outras pessoas, ou até mesmo buscando uma autopunição.

A automutilação pode ter uma ligação com vários fatores. Para Giusti (2013), algumas dessas alterações podem ser funcionais e neurobiológicas, já que os sistemas com 
principal associação a este comportamentos são serotoninérgicos, dopaminérgicos e opióides.

O sistema serotoninérgico quando apresenta problemas, são tidos como uma regra para expressão da automutilação. Estudos têm mostrado uma relação inversa entre o comportamento impulsivo-agressivo e a função do sistema serotoninérgico cerebral. (GIUSTI, 2013).

Quando há uma modificação da função do sistema dopaminérgico, pode ocasionar o início da automutilação. Para Giusti (2013) isto inclue alterações no estímulo dopaminérgico do aumento da sensibilidade dos receptores de dopamina. No sistema opioide, uma característica comum é a analgesia total ou parcial durante e após a automutilação (GIUSTI, 2013). Esse sistema tem como função a percepção de dor e analgesia relacionados ao extremo. Existem duas hipóteses relacionadas às alterações no sistema opioide e a automutilação, a primeira fala sobre a dependência aos opioides endógenos e o aumento da tolerância estímulos dolorosa. Esta hipótese da dependência sugere que as pessoas que se mutilam têm sensibilidade cerebral normal ao opioides. Entretanto, devido à extensiva estimulação desse sistema e à liberação de opioides durante a automutilação, o paciente desenvolve sintomas de abstinência e necessita se mutilar para ativar novamente o sistema opioide (GIUSTI, 2013). A segunda hipótese, para Giusti (2013), envolve alterações na percepção da dor. Esta sugere que há um aumento na ativação do sistema opioide que leva a um aumento na concentração de opioide e, consequentemente, na diminuição da percepção da dor.

É necessário que considerar todos estes fatores, para que haja um maior entendimento a respeito do comportamento de mutilação, e que dessa forma possa buscar o tratamento de alguns pacientes. Os elementos que tem influência na automutilação são vários, dentre eles destacam-se os elementos biológicos, que podem se relacionar a fadiga ou insônia. Os elementos psicológicos, que se detêm aos antecedentes cognitivos, afetivos e comportamentais como, os pensamentos automáticos e imediatos, elementos estes que podem vir antes da automutilação. 
No que diz respeito aos antecedentes afetivos internos, são identificados; as emoções afetadas pela automutilação; se os antecedentes que originam estas emoções podem ser reduzidos em frequência e intensidade e como podem essas emoções ser geridas de forma mais eficaz, com recurso a competências alternativas (LOURENÇO, 2008, p. 23).

Os antecedentes comportamentais, são as ações que resultam na automutilação, são hábitos, práticas e rituais que são feitos antes da automutilação. Estes padrões de comportamento podem se repetir tanto que viram um hábito, assim se tornando difíceis de interromper.

De fato, a cada um dos inúmeros formatos de automutilação descritos corresponde todo um conjunto de características específicas e associadas a diferentes funções psicológicas, uma vez que todo o comportamento automutilante se encontra agregado a um aumento de fatores de risco e dificuldades de adaptação específica (LOURENÇO, 2008, p.30).

A automutilação pode se manifestar tanto na situação de uma doença, quanto na ausência desta. Ela está presente em várias doenças e de várias formas diferentes, a identificação desses formatos pode contribuir para entender o que causou esses comportamentos e também como seguir com o tratamento. A intensidade, forma, agressividade, envolvimento emocional, magnitude e o grau de dano corporal variam de caso para caso, assim é necessária uma análise detalhada de cada caso para encontrar o tratamento adequado.

A automutilação pode ser dividida em duas categorias: sancionamento cultural e automutilação desviante. Os rituais culturalmente sancionados incluem o uso de piercings, recurso a rituais que envolvem situações de automutilação, circuncisão, entre outros. São comportamentos aceites apenas na cultura a que pertencem, e servem frequentemente para marcar a passagem entre diferentes estágios da vida ou sob a forma de comunicação com algum poder superior. A segunda categoria engloba a automutilação de base patológica, definida como alteração ou destruição deliberada do tecido corporal sem intenção suicida (STONE, 2003 apud LOURENÇO, 2008, p.2).

Tem uma grande importância, segundo Lourenço (2008) observar o grau de severidade do comportamento automutilante e para ele este se divide em três: severa estereotipada e superficial. 
A automutilação severa: Neste tipo de automutilação estão os atos esporádicos onde uma área significativa do corpo é destruída, nomeadamente situações de castração, amputações, etc. Este tipo de comportamento é quase exclusivamente encontrado em pacientes psicóticos.

A automutilação estereotipada: Esse tipo é mais provável que ocorra na presença de outro indivíduo. Está acompanhada de um padrão específico de expressão simbólica e ritmada, ela ocorre mais frequentemente entre indivíduos que estão hospitalizados com atraso mental, bem como objeto de distúrbios neurológicos e psiquiátricos como, por exemplo, o autismo, síndrome de Tourette, de Lesch Nyhan, etc. Nos formatos mais comuns surgem situações de bater com a cabeça contra as paredes, mastigar os próprios dedos ou pressionar os globos oculares.

Ainda de acordo com Lourenço (2008), a automutilação superficial é a forma mais comum de automutilação é pode ser dívida em três categorias diferentes: a superficial compulsiva, a episódica e a repetitiva.

A automutilação superficial compulsiva tende a acontecer várias vezes por dia e é repetitiva e ritualista. A automutilação episódica refere-se a comportamentos que ocorrem apenas esporadicamente. No que diz respeito à terceira categoria, a automutilação repetitiva inclui pacientes com diagnóstico de síndrome de automutilação repetitiva ou síndrome de automutilação deliberada (LOURENÇO, 2008, P. 3).

A automutilação vem se mostrando cada vez mais como um problema de saúde pública, uma vez que, o número de indivíduos vem aumentando significamente, assim torna-se fundamental desenvolver um conjunto de elementos preventivos e interventivos que tenha como base as informações já adquiridas e na observação de cada caso particular. Por muitas vezes este ato se mostrou ligado a distúrbios alimentares, problemas com bebidas, traumas de infância, isolamento social e até mesmo a determinados problemas psicológicos.

No seguimento da descrição das limitações relativas aos parâmetros metodológicos, éticos e práticos com os quais a comunidade científica se depara no estudo da automutilação, não é possível deixar de considerar também as dificuldades encontradas pelos prestadores de 
cuidados na gerência de comportamentos de automutilação. [...] (LOURENÇO, 2008, p.31).

É um desafio para muitos profissionais, os quais deveriam estar preparados quando se deparassem com tal situação. Apesar da importância, ainda não há um consenso na terminologia e definição em relação à automutilação, isto pode afetar a interpretação da informação estatística vinda da investigação. Se não for diferenciado e contextualizado o que o indivíduo apresenta, é difícil que haja uma distinção entre os indivíduos que apresentam o comportamento automutilante e aqueles que são objetos de tentativas de suicídio que não obtiveram êxito, isto pode atrapalhar e induzir a erros de estudos desenvolvidos sobre essa temática.

Assim esta falta de diferenciação em relação à definição de automutilação, pode ter um grande impacto negativo à prática dos profissionais de saúde, uma vez que, para os profissionais promoverem o tratamento adequado e eficaz para os indivíduos que apresentam comportamento automutilante é necessário que se conheça sobre determinado comportamento, seus impactos na vida do indivíduo, quais os fatores que desencadearam estes, assim desenvolvendo um trabalho eficiente entre o indivíduo e o profissional. Para Lourenço (2008), a terminologia da automutilação é de grande importância e que a noção de linguagem merece uma maior consideração.

Segundo o autor George (2011), a saúde pública na atualidade tem a necessidade de uma convivência harmônica, aberta e respeitosa com a comunicação social. Com o interesse de assegurar a promoção de saúde à população e, assim, criar condições favoráveis ao desenvolvimento humano. A saúde pública contemporânea objetiva passar informações e conscientizar os cidadãos dos riscos, mas ela também busca passar tranquilidade e serenidade durante o acolhimento. Então desta forma está o funcionamento dos dispositivos que procuram assegurar a informação pública, nomeadamente por uma linha telefônica interativa e que possui um fácil acesso, ligada à Internet. Dimensão informativa a completar e a potenciar, naturalmente, por órgãos de comunicação social de qualidade.

A saúde pública nova é um conceito inspirado no modelo social, e que também tem em si disciplinas científicas distintas e, também novas tecnologias, termo este que é 
moldado através só processo de mudança. E recebem contribuição da sociologia, da antropologia, da biologia e da matemática, entre outras ciências.

O conceito de saúde pública tem evoluído com o passar do tempo. "Ocupa-se, assim, de todos os cidadãos e organiza-se em todas as instituições do sistema de saúde (unidade de saúde familiar ou estabelecimentos hospitalares ou, ainda, de cuidados continuados)" (GEORGE, 2011, p.9).

A saúde pública atual deixou de ficar presa apenas em atividades de prevenção primária e terciária, e passou também a ser considerada de grande importância nas etapas do diagnóstico e do tratamento de doenças, buscando uma série de medidas apropriadas para desenvolver uma estrutura social capaz de proporcionar a todos os indivíduos a condição de saúde necessária. Esta definição é utilizada também pela Organização Mundial de Saúde, o principal órgão internacional que visa à manutenção do bem-estar físico, psíquico e social (JUNIOR, 2006-2018).

Assim como os outros serviços que envolvem o contato direto com o indivíduo, o profissional se depara com um indivíduo que se encontra em situação de sofrimento psicológico, segundo Lourenço (2008), esses profissionais lidam com indivíduos que apresentam comportamentos de risco, quer em nível de investigação, quer em contexto de gestão e tratamento, e como consequência se encontrava todo um conjunto de parâmetros de fundo metodológico, ético e prático que podem limitar o progresso do entendimento de várias características do comportamento automutilante, assim como o desenvolvimento de formas de prevenção e intervenção frente a essa situação.

Para o tratamento de indivíduos em situação de automutilação, um recurso que tem sido largamente usado, são os fármacos, exemplo: fluoxetina, e estudos efetuados referem que estes poderão também ser tratamentos eficazes de manutenção dos resultados.

A reversão de comportamentos tem sido sugerida como tratamento comportamental promissor para a automutilação, dada a sua eficácia no tratamento de comportamentos problemáticos habituais. A reversão de 
comportamentos consiste em múltiplos componentes que incluem treino de competências da percepção de comportamentos habituais, treino de relaxamento para ajudar a reduzir a tensão, treino de resposta competitiva, onde os sujeitos aprendem a realizar movimentos incompatíveis com os comportamentos habituais, gestão de contingências, e por último treino de generalização para aprender a controlar comportamentos habituais em situações normais do dia-a-dia (LOURENÇO, 2008, p. 48).

Ainda seguindo Lourenço (2008), considera que, o método da terapia favorece o entendimento acerca do enfoque nos problemas. Os pacientes relataram que a terapia é o método que melhor é adaptado a seus problemas específicos. Durante o tratamento de indivíduos com comportamentos automutilantes são adotadas medidas de proteção por clínicas e por vários profissionais e que objetivam a prevenção e redução do risco de lesões resultantes de automutilação.

Nesta prática são utilizados dois tipos de medidas preventivas, segundo Lourenço (2008), a primeira, que é conhecida como medida restritiva, é necessário que o indivíduo use o equipamento específico para restringir a movimentação, esta restrição visa minimizar ou eliminar o risco do comportamento alvo. Mesmo chegando a diminuir estes comportamentos, essa medida tende a ser aversiva, punitiva e intrusiva, e podem causar uma restrição na participação de indivíduos em atividades educacionais e sociais. E ainda causar uma dependência a estes métodos restritivos. E no segundo tipo de medida preventiva são construídas estratégias, que não use a restrição e que haja uma redução dos comportamentos.

Mas existem outros métodos que diferentes do último, não usam formas de restrição da movimentação do indivíduo. Construindo estratégias para que haja uma redução dos comportamentos como, por exemplo, de não deixar as unhas compridas, para que minimize os arranhões. As lesões que são causadas pelo ato de arrancar os próprios cabelos, podem ser reduzidas deixando o cabelo curto, assim dificultando arrancá-los. Essas estratégias de prevenção requerem uma análise detalhada do comportamento, para que se possam identificar os fatores de riscos e formas para reduzir ou eliminar estes. Estas formas de medidas são utilizadas para minimizar os danos autoinfligidos 
e para que estes não necessitem de cuidados médicos e imediatos antes de serem implementados tratamentos.

No acesso à informação relativa à natureza das funções e mecanismos característicos de cada caso de automutilação em particular deve recorrer-se a uma estrutura por intermédio da qual se foca, numa primeira fase, o relacionamento terapêutico, e de seguida o historial e especificidades do comportamento bem como as suas funções intra e interpessoais, aliado aos antecedentes e consequências. Por fim são identificados tipos de automutilação atípicos e especialmente alarmantes (WALSH, 2007, apud LOURENÇO, 2008, p.18).

Ainda de acordo com os estudos e Lourenço (2008), o processo em que se avaliam os comportamentos automutilantes podem se dar em duas fases, que são: resposta informal e o acesso aos detalhes da automutilação. Assim identificados os detalhes da automutilação, é necessário que determine os antecedentes ambientais, biológicos e psicológicos do comportamento automutilante. Esses determinantes são de grande relevância, pois podem ser usados para deduzir atos de automutilação que possam vir a acontecer e assim há a oportunidade de praticar atos de substituição.

Para grande parte destes indivíduos, os antecedentes ambientais podem incluir problemas com conflitos relacionais e cortes relacionais, ou frustrações relacionadas ao desempenho profissional ou escolar. Já para outros, esses desencadeadores podem ser experiências diárias que despertam as memórias traumáticas ou flashback ao analisar os desencadeadores de comportamento automutilante é importante avaliar as consequências. As subcategorias dessa dimensão também são ambientais, biológicas e psicológicas (LOURENÇO, 2008).

Mesmo o procedimento de extinção, mostrando uma eficácia rápida no tratamento de automutilação, outros estudiosos se mostram contrários a esta opção por duas razões:

A primeira prende-se com a sua real eficácia, na medida em que, de acordo com estudos prévios, seria menos eficaz que a terapia de eletrochoques e reforço diferencial. Em segundo lugar, prende-se com razões de segurança, especialmente durante o procedimento de extinção propriamente dito. De acordo com alguns autores, é importante proteger a segurança do paciente, já que um fenômeno comum na extinção se prende com o facto de o comportamento normalmente piorar 
antes de melhorar, o que pode ser perigoso para o paciente (LOURENÇO, 2008, p.14).

Assim pode-se chegar à conclusão que os métodos de extinção não são bem aceitos pelos estudiosos, estes alegam que os métodos alternativos produzem um melhor resultado no tratamento da automutilação que os métodos de extinção. O acompanhamento terapêutico torna-se muito eficaz no tratamento da automutilação.

Consideram ainda os benefícios do manual terapêutico, que postula que o terapeuta deve levar os sintomas e sofrimento dos pacientes a sério e ao mesmo tempo responsabilizá-los pelas suas próprias vidas, bem como pela terapia. O manual contém ainda as técnicas necessárias para melhorar as competências dos sujeitos, para que possam lidar melhor com os sintomas e vidas sociais de melhor forma. Postulam que, o método é respeitoso e leva os pacientes a sério, na medida em que o terapeuta aprende a levar os pacientes a sério, tentando compreender as suas dificuldades noutra perspectiva, e o método enfatiza o respeito e a necessidade de valorizar o sofrimento dos pacientes (LOURENÇO, 2008, p.39).

Os terapeutas afirmam que durante a terapia, os mesmos constroem uma nova visão mais positivas dos pacientes e assim há uma melhor compreensão.

Sentem que as suas crenças sobre os pacientes se alteraram significativamente, de problemáticos e manipuladores para o fato de estarem a dar o seu melhor, dadas as circunstâncias. Comportamentos como agitação, automutilação ou comportamento antissocial já não são encarados como manipulação deliberada, mas enquanto incapacidade de agir de outra forma derivado aos sintomas e situação de vida complicada por ausência de competências (LOURENÇO, 2008, p.39).

Assim se mostra de fundamental importância estudos sobre esta temática para a construção de tratamentos adequados para essa problemática, pois só através do conhecimento se constrói uma base sólida para construir uma definição que abrange todas as características que vem sendo observadas e muitas que ainda estão por vir. E que apesar de um comportamento que vem de longa data na história é um assunto relativamente novo na comunidade científica, mas que vem despertando cada vez mais interesse, por mostrar recorrência crescente, se fazendo necessário o desenvolvimento de formas de tratamentos eficazes e abordagens que auxiliem os profissionais de saúde pública no enfrentamento dessa manifestação através do 
corpo, para externar o que este está sentindo. Assim esse comportamento que por muitas vezes durante a história foi visto como algo que fazia parte de rituais e momentos que o indivíduo passava, agora é visto de forma mais ampla e como um problema se saúde pública.

\section{CONSIDERAÇÕES FINAIS}

$\mathrm{Na}$ construção da subjetividade do indivíduo na atualidade, pode ser observada a manifestação de sofrimentos e transtornos psicológicos através da comunicação corporal. A atenção dada a essa temática vem aumentando diariamente, tendo como ferramenta importante à divulgação dada pela mídia, mostrando assim o crescimento dos casos de indivíduos com automutilação na sociedade contemporânea, onde se torna um problema de saúde pública, uma vez que, há um aumento significativo de indivíduos, principalmente adolescentes que se mutilam.

O conceito de saúde pública está atrelado à ação de informar e conscientizar a população sobre os riscos, como também sobre as práticas de prevenção, buscando um olhar integral ao indivíduo que está inserido em diversos fatores que podem ocasionar em sua perca de saúde.

Indivíduos que apresentam o comportamento automutilante, geralmente o manifestam durante a fase da adolescência, onde muitas vezes as práticas diminuem, podendo até mesmo sessar, sem muitas vezes necessitar de intervenção profissional. Assim, em grande parte dos casos, pode existir uma associação com os conflitos vivenciados nessa fase da vida, como com vários outros fatores, entre eles: como alterações funcionais e neurobiológicas.

A automutilação já foi confundida com a tentativa do suicídio, porém estudos mostram que o indivíduo quando se mutila está em uma tentativa de buscar uma regulação de afetos, procurando se acalmar ou liberar pressão emocional que se acumulou dentro de significados, e este indivíduo também pode estar tentando criar limites interpessoais, ou até mesmo buscando uma autopunição. A autopunição pode se manifestar tanto na doença quanto em sua ausência. 
Os profissionais de saúde, que trabalham diretamente com essa demanda, precisam estar preparados para ter um olhar amplo, analisando todos os fatores envolvidos neste caso e também um olhar individualizado observando cada caso como diferente do outro, e assim podendo proporcionar um tratamento mais eficaz. Nesse sentido, nota-se a importância do desenvolvimento de estudos sobre a automutilação e a capacitação dos profissionais para o enfrentamento desta problemática que vem crescendo consideravelmente.

\section{REFERÊNCIAS}

ARAÚJO, J. F. B.; CHATELARD, D. S.; CARVALHO, I. S.; VIANA, T. de C. V. O Corpo na Dor: Automutilação, masoquismo e pulsão. 2016. Disponível em: $<$ http://pepsic.bvsalud.org/pdf/estic/v21n2/a12v21n2.pdf>. Acesso em: 13/07/ 2018 às $22 \mathrm{~h} 08 \mathrm{~m}$.

BERNARDES, S. M. Torna-se (in)visível: um estudo na rede de atenção psicossocial de adolescentes que se automutilam. [Dissertação] Universidade Federal de Santa Catarina. Centro de Ciências da Saúde. Mestrado profissional em saúde mental e atenção psicossocial. Florianópolis, 2015.

BIZRI, R. Z. Self Cutting: uma visão psicanalítica sobre os transbordamentos pulsionais no corpo. 2014. Disponível em: <https://docplayer.com.br/36335028-Selfcutting-uma-visao-psicanalitica-sobre-os-transbordamentos-pulsionais-nocorpo.html >. Acesso em 03/08/2018 às 15h26m.

CEDARO J. J.; NASCIMENTO J. P. G. Dor e gozo: relatos de mulheres jovens sobre automutilações. Psicologia USP, São Paulo, 2013. Disponível em: $<$ http://www.revistas.usp.br/psicousp/article/view/63404/66147>. Acesso em 01/08/2018 às $13 \mathrm{~h} 15 \mathrm{~m}$.

COSTA, A. Tatuagem e nossas marcas corporais: atualização do sagrado. $3^{\circ}$ edição. São Paulo, SP. Casa do psicólogo. 2014. 
FAVAZZA, A. (1996). Corpo sob cerco: automutilação e modificação corporal em cultura e psiquiatria. Baltimore, Maryland: The Johns Hopkins University Press. (Trabalho original publicado em 1987).

FERNANDES, H. M. O corpo e os ideais do clínico contemporâneo. Editora Casa do Psicólogo, 2011.

FERREIRA, V. S. Resgates sociológicos do corpo: esboço de um percurso conceptual. Análise Social, Lisboa, v. 208, n. 3, p. 2182-2999, 2013. Disponível em: < http://analisesocial.ics.ul.pt/documentos/AS_208_a01.pdf>. Acesso em 01/07/2018 às 23h32m.

FROIS, E; MOREIRA, J.; STENGEL, M. Mídias e a imagem corporal na adolescência: o corpo em discussão. Maringá, v. 16. n. 01, jan/mar 2011. Disponível em: < http://www.scielo.br/pdf/pe/v16n1/a09v16n1.pdf>. Acesso em: 24/07/2018.

GEORGE, F. Sobre o conceito de saúde pública, Lisboa, Fevereiro de 2011. Disponível em: <file:///C:/Users/Windows\%2010/Downloads/i019310.pdf>. Acesso em $13 / 08 / 2018$ às $14 \mathrm{~h} 44 \mathrm{~m}$.

GIL, A. C. Métodos e técnicas de pesquisa social. 6. Editora Atlas S.A. - 2008.

GIUSTI, J. S. Automutilação: Características clínicas e comparação com pacientes com transtorno obsessivo-compulsivo. 2013. Tese (doutorado) - Faculdade de Medicina da Universidade de São Paulo. Programa de Psiquiatria. São Paulo: USP. 2013.

JUNIOR, A. G. Saúde pública. Informe escola, navegando e aprendendo, 2006-218. Disponível em: <https://www.infoescola.com/saude/saude-publica/>. Acesso em: 15/09/2018.

LAKATOS, E. M.; MARCONI, M. A. Fundamentos de metodologia científica, 5ำ edição, Editora Atlas, São Paulo, 2003. 
LOURENÇO, V. S. G. Para uma compreensão dos comportamentos de automutilação. [Dissertação]. Instituto Superior de Psicologia Aplicada. 2008. Disponível em: < http://repositorio.ispa.pt/bitstream/10400.12/4725/1/12379.pdf>. Acesso em: $23 / 08 / 2018$ às $18 \mathrm{~h} 19 \mathrm{~m}$.

MATARUNA, L. Imagem Corporal: noções e definições. Campinas, 2004.

MENNINGER, K. (1966). Man against himself. New York, NY: Harcourt Brace Jovanovich Publishers. (Trabalho original publicado em 1938).

NETO, L. Prática de automutilação entre adolescentes se dissemina na internet e preocupa pais e escola. 2014. Disponível em: < https://oglobo.globo.com/sociedade/saude/pratica-de-automutilacao-entreadolescentes-se-dissemina-na-internet-preocupa-pais-escolas-14050535 >. Acesso em: 08/08/ 2018 às 00h56m.

NÓBREGA, T. P. Corpo, percepção e conhecimento em Merleau-Ponty. Estudos de Psicologia. 2008, 13 (2), 141-148. Rio Grande do Norte. Disponível em: < http://www.scielo.br/pdf/epsic/v13n2/06.pdf>. Acesso em: 23/08/2018 às 23h15m.

ORGANIZAÇÃO MUNDIAL DA SAÚDE: classificação estatística internacional de doenças e problemas relacionados à saúde. CID-10. 5 edição. São Paulo. 1999.

SILVA, P. M. Automutilação na adolescência: acesso ao tratamento médico como direito fundamental. Rio de Janeiro. 2012. Disponível em: < http://www.mutuadosmagistrados.com.br/sitemutua/wpcontent/uploads/2014/07/AUTOMUTILACAONAADOLESCENCIA.pdf>. Acesso em:26/08/2018 às $23 \mathrm{~h} 00 \mathrm{~m}$.

TURNER, V.J. Secret Scars: uncovering and understanding the addiction of self-injury. Minnesota: Hazelden, 2002.

Enviado: Junho, 2019.

Aprovado: Dezembro, 2019. 